\title{
Heparinized Chitosan Stabilizes the Bioactivity of BMP-2 and Potentiates the Osteogenic Efficacy of Demineralized Bone Matrix
}

\section{Soyon Kim}

University of California Los Angeles

Jiabing Fan

University of California Los Angeles

Chung-Sung Lee

University of California Los Angeles

Chen Chen

University of California Los Angeles

Ksenia Bubukina

University of California Los Angeles

Min Lee ( $\boldsymbol{\nabla}$ leemin@ucla.edu )

University of California Los Angeles

\section{Research}

Keywords: heparin, hydrogel, bone morphogenetic protein, demineralized bone matrix, osteogenesis

Posted Date: February 21st, 2020

DOI: https://doi.org/10.21203/rs.2.21464/v2

License: () (1) This work is licensed under a Creative Commons Attribution 4.0 International License.

Read Full License

Version of Record: A version of this preprint was published at Journal of Biological Engineering on March 6th, 2020. See the published version at https://doi.org/10.1186/s13036-020-0231-y. 


\section{Abstract}

Background: Demineralized bone matrix (DBM), an allograft bone processed to better expose osteoinductive factors such as bone morphogenetic proteins (BMPs), is increasingly used for clinical bone repair. However, more extensive use of DBM is limited by its unpredictable osteoinductivity and low bone formation capacity. Commercial DBM products often employ polymeric carriers to enhance handling properties but such carriers generally do not possess bioactive functions. Heparin is a highly sulfated polysaccharide and is shown to form a stable complex with growth factors to enhance their bioactivities. In this study, a new heparinized synthetic carrier for DBM is developed based on photocrosslinking of methacrylated glycol chitosan and heparin conjugation.

Results: Heparinized chitosan exerts protective effects on BMP bioactivity against physiological stressors related to bone fracture healing. It also enhances the potency of BMPs by inhibiting the activity of BMP antagonist, noggin. Moreover, heparinized chitosan is effective to deliver bone marrow stromal cells and DBM for enhanced osteogenesis by sequestering and localizing the cell-produced or DBM-released BMPs.

Conclusions: This research suggests an essential approach of developing a new hydrogel carrier to stabilize the bioactivity of BMPs and improve the clinical efficacy of current bone graft therapeutics for accelerated bone repair.

\section{Background}

Autologous bone grafts have been considered the "gold standard" for bone regeneration. However, bone grafts are limited by donor sites morbidity, extended operative time, and autogenous supply[1]. Demineralized bone matrix (DBM) is processed to reduce immunogenicity and has been used widely in the orthopedic industry $[2,3]$. During processing, the mineral content of DBM is removed to better expose the osteoinductive factors present in DBM particularly bone morphogenetic proteins (BMPs), powerful regulators for bone formation[4]. However, the processing also eliminates stem cells and the osteoinductivity of DBM can be variable, and clinical failure in orthopedic applications is reported high compared to autograft bone[5]. Moreover, the released osteoinductive cytokines (BMPs) will easily lose their biological function due to their inherent proteolytic and chemical hydrolysis in vivo[6]. Commercially available DBM products often use liquid carriers but they have poor irrigation resistance following implantation, diminishing a localized effect of osteogenic components at the bone defects[7]. Exogenous recombinant BMPs can be employed to improve osteogenic effects of DBM[8]. However, their clinical applications require a supraphysiological concentrations potentially leading to various side effects[9] such as undesired ectopic bone development[10], cyst formation[11], osteoclastic resorption[12], or adipogenesis[13]. Therefore, there is a need to develop an alternative biological carrier that can enhance the potency of BMPs present in DBM and better guide the osteogenic response at the defect site.

Heparin is a highly sulfated polysaccharide in extracellular matrix and has been widely studied as a delivery carrier of growth factor proteins including BMPs[14-16] due to its high binding affinity to the 
proteins. It has also been shown to maintain or enhance the biological activities of growth factors by forming a stable complex[17]. Heparin can act as a catalyst to form the signaling complexes of BMPs by recruiting type II receptor subunits, even though it has no direct activation role[18]. Heparin is also known to regulate BMP functions by interacting with BMP antagonists such as noggin. Heparin has been shown to regulate the diffusion of noggin in vivo and form the gradients of BMP-2 activity by inhibiting its binding to BMP[19-21].

Chitosan is a biocompatible and biodegradable polysaccharide[22] that has been well studied in bone tissue engineering applications[23, 24]. Chitosan can be easily modified with

different functional groups and readily forms three-dimensional networks by simple processing such as thermogelling[25] or photocrosslinking[26]. Recent studies report the use of chitosan as composites with other polymers or ceramics for improved mechanical properties[27].

In this work, we report a novel heparinized synthetic carrier for DBM that can stabilize and enhance the bioactivity of BMPs for increased osteoinduction. We previously reported a light-inducible hydrogel system composed of methacrylated glycol chitosan (MeGC) as a photocrosslinkable polymer and riboflavin as a photoiniator[26]. The MeGC system is highly biocompatible to support the growth of encapsulated cells and can be readily modified with different functionalities such as cell-adhesivemotifs[23] or matrix-degradable-unit[28]. Herein, we immobilized heparin to MeGC by simple chemical conjugation and investigated whether the heparinized MeGC can have protective effects on BMP-2 for osteogenesis under physiological stressors found under bone fracture healing or in the presence of BMP antagonist, noggin. We also demonstrated the potential of heparinized MeGC as biological carriers for DBM to enhance osteogenic efficacy.

\section{Results}

\section{Characterization of Heparinized Chitosan}

Hep-MeGC was prepared by conjugation of heparin into MeGC via EDC chemistry and a hydrogel was fabricated by visible blue light crosslinking with a riboflavin initiator (Figure 1a). The successful modification of heparin was confirmed by ${ }^{1} \mathrm{H}$ NMR that showed the increment of sulfonate peaks (Figure 1b). The FTIR spectra of Hep-MeGC exhibited the peak of $\mathrm{SO}^{3-}$ at $1200 \mathrm{~cm}^{-1}$, confirming the successful conjugation of heparin (Figure 1c). The stable and homogenous functionalization of heparin in a chitosan hydrogel was verified by toluidine blue that stained the negatively charged sulfonate groups (Figure 1d). Heparinization enhanced the osteogenic efficacy of hydrogels as demonstrated by intensified staining of ALP and alizarin red S. The ability of heparinized chitosan to sequester endogenous BMP-2 secreted by the encapsulated BMSCs was further detected by immunofluorescence staining (Figure 1e). These results suggested that the improved osteogenesis by heparin modification was potentially induced by BMP-2 sequestering of hydrogels. 


\section{Heparinized Chitosan Stabilizing BMP-2 Bioactivity}

The BMSCs were used to evaluate the bioactivity of BMP-2 associated with heparinized chitosan after the exposure to different stressed conditions (Figure 2a). The BMP-2 was incubated with PBS, MeGC, or HepMeGC in physiological pH for one week at $37^{\circ} \mathrm{C}$ or in MMP-9 solution for $16 \mathrm{~h}$ at $37^{\circ} \mathrm{C}$ to mimic protease-enriched bone healing environments. The ALP staining and activity tests were performed after the treatment of with BMP-2 incubated for 4 days to verify the bioactivity of BMP-2 after exposure to the stressors. The groups without BMP-2 and with freshly prepared BMP-2 were used as a negative and a positive control, respectively. The ALP activity was gradually enhanced with the addition of MeGC and Hep-MeGC. This is possibly due to the increased half-life of BMP-2 with the addition of chitosan or heparinized chitosan in comparison to PBS group (Figure 2b) under both prolonged and MMP conditions. The bioactivity of treated BMP-2 dropped significantly in all groups but Hep-MeGC showed the higher bioactivity compared with MeGC and PBS. Hep-MeGC demonstrated higher protective effects compared with MeGC and PBS in both prolonged and MMP-9 treated conditions.

\section{Heparinized Chitosan Protecting BMP-2 From Noggin}

Noggin is a BMP antagonist and inhibits BMPs signaling. The BMSCs were culture with BMP-2 (100 ng $\left.\mathrm{mL}^{-1}\right)$ and various concentrations of noggin $\left(0,30,100\right.$, and $\left.300 \mathrm{ng} \mathrm{mL}^{-1}\right)$. The ALP expression started to decrease with the addition of $30 \mathrm{ng} \mathrm{mL}^{-1}$ noggin in PBS group (Figure 3a and Figure S1). The BMSCs incubated with MeGC exhibited higher ALP expression compared with PBS only group with $30 \mathrm{ng} \mathrm{mL}^{-1}$ noggin. Furthermore, BMSCs incubated with Hep-MeGC have more intensified staining up to the addition of $100 \mathrm{ng} \mathrm{mL}^{-1}$ noggin. Then, we investigated whether the expression level of noggin as an early response gene of BMP-2[29] maintained with the addition of MeGC or Hep-MeGC. After $1 \mathrm{~h}$ of stimulation of BMP2 , noggin mRNA expressions of BMSCs were increased regardless of chitosan supplement (Figure 3b). The level of noggin expression after $72 \mathrm{~h}$ decreased for BMP only and MeGC groups but did not drop for Hep-MeGC group. These results indicated that heparinized chitosan enhanced BMP signaling by protecting it from noggin.

\section{Characterization of Hydrogel-DBM composite}

DBM was incorporated in heparinized chitosan to form osteoinductive hydrogel-DBM composites. The chitosan hydrogel was mixed with various ratio of DBM and the incorporated DBM was homogenously distributed in the hydrogel-DBM composite (Figure 4a). Compressive modulus of the composites increased with the addition of DBM in a dose-dependent manner (Figure 4b). Mechanical strength of the composites also increased with the addition of DBM but was not significantly different based on hydrogel types (MeGC or Hep-MeGC). Water content of the composites decreased with the addition of 
DBM but was not affected by hydrogel types (Figure 4c). From these results, physical properties of the composites were not significantly affected by hydrogel types but the incorporation of DBM.

\section{Proliferative Potential of Cells in Hydrogel-DBM composite}

The live/dead images of BMSCs in composites were monitored for two weeks. High cell viability over $90 \%$ was observed for all groups at day 0 . There was no significant change in cell viability over the culture period while cell viability decreased to $85 \%$ for DBM-free groups by day 14 (Figure S2). The morphology of cells was significantly changed with the addition of DBM which showed extended spreading alongside of DBM (Figure 5a). The cell spreading in the composites also influenced the overall growth as confirmed by the alamarBlue result (Figure $5 b$ ). The proliferative potential of cells increased with the incorporation of DBM in a dose dependent manner. In order to observe the interaction of DBM with the encapsulated BMSCs in composites, H\&E staining was performed on the histological section (Figure $5 c$ ). An intense purple color was observed in the DBM hydrogel composite, indicating proliferation of encapsulated cells, while cell-free constructs stained with light- or dark-pink (Figure S3).

\section{Osteogenic Effect of Hydrogel-DBM composite}

The hydrogel-DBM composites provided osteoinductive environment to the encapsulated BMSCs by sequestering the cell-produced or DBM-released BMPs. The encapsulated BMSCs in composites were stained with ALP and alizarin red S at day 7 and day 21, respectively (Figure 6a). The strengthened ALP production and activity were observed with the addition of DBM, and the trend was more escalated when heparinized chitosan was used. The mineralization result verified the augmented calcium deposition with the incorporation of DBM as well as heparin functionalization. The DBM and heparinization also upregulated the osteogenic gene expression (Figure 6b). The Runx2, a transcription factor associated with osteoblast, significantly enhanced at day 4 in MeGC-DBM $2 \%$ and heparinized groups (Hep-MeGC, Hep-MeGC-DBM 1\%, and Hep-MeGC-DBM 2\%). The ALP expression was more dynamically increased with the addition of DBM as well as heparinization. The late osteogenic marker, $O C N$, also confirmed the enhanced osteogenesis with heparin and DBM incorporation.

\section{Discussion}

Although its clear utility is reflected in its market position for skeletal reconstruction, more extensive use of DBM is hampered by its unpredictable osteoinductivity and low bone formation rate due to source- or process-related variations[30,31]. Current DBM products often employ polymeric carriers for better handling properties but such excipients generally have no bioactive function[7]. In this work, we demonstrated that chemically functionalized chitosan with heparin (Hep-MeGC) can stabilize BMP-2 and increase its biological activity for osteogenesis. Moreover, Hep-MeGC can augment endogenous BMP 
activity by sequestering and localizing the cell-produced BMPs that should synergistically stimulate osteogenesis induced by DBM.

In order to investigate the underlying mechanism of heparinized chitosan to stabilize BMP bioactivity, we incubated rhBMP-2 with MeGC or Hep-MeGC under therapeutically related stressors. First of all, Hep-MeGC maintained BMP-2 bioactivity in the prolonged incubation condition, but the bioactivities in PBS and MeGC groups were reduced significantly (Figure 2a). This was possibly due to the increased half-life of BMP-2 with Hep-MeGC which was verified by quantification of BMP-2 at both prolonged and MMP-treated conditions (Figure 2b). BMP-2 quantification near cell layer area were also measured to verify that BMP-2 was not bound near cell layer but degraded (Figure S4). The addition of heparinized chitosan maintained the higher concentration of BMP-2 in culture medium compared with chitosan only or nontreated groups. We also assessed the amount of BMP-2 in cell layers which exhibited less than $5 \%$ in the presence or in the absence of heparinized chitosan. This suggested the vanishing of BMP-2 was not a result of accumulation on the cell layer but a result of degradation[21]. The observed stabilizing effect of unmodified MeGC could be attributed to intermolecular interactions between MeGC and BMP-2 to form chitosan-BMP complexes, preventing protein denaturation and aggregation, thus conferring greater stability.

Many proteolytic enzymes such as MMP-2, MMP-9, or cathepsin-K were involved in bone remodeling process[32], and MMPs were key degrading enzyme expressed in either physiological[33] or pathological conditions including osteoarthritis[34], and osteoporosis[35]. The concentration of MMP-2 increased around two times, and MMP-9 increased around ten times under bone formation and disease environment[36-38]. In this MMP-9 enriched condition, we observed all PBS, MeGC, and Hep-MeGC groups suffered decrement of BMP-2 bioactivity (Figure 2a). However, BMP-2 activity in Hep-MeGC was significantly higher than PBS and MeGC groups, indicating the most protective effects of Hep-MeGC under enzymatic stressors. MeGC only group had a minimal protective effect, suggesting interaction through heparin is essential to stabilize BMP-2 bioactivity rather than interacting with chitosan chains.

Hep-MeGC may also interact with BMP antagonists to regulate BMP functions. Noggin is a specific antagonist of BMP-2 and restricts its interaction with receptors to regulate increased levels of BMP stimuli[29]. Noggin is also known to bind S domains of heparan sulfate like BMP-2[39, 40] and its interaction with heparan sulfate proteoglycan can form the activity gradients of BMP-2 by modulating the diffusion of noggin[20]. As such, heparin enabled BMPs to preserve longer in the culture medium indeed in the presence of noggin (Figure 3a and Figure S1)[21].

Lastly, we evaluated whether heparinized chitosan can enhance the osteogenic efficacy of the incorporated DBM. The compressive modulus of hydrogel-DBM composite significantly increased with the incorporation of $1 \%(\mathrm{w} / \mathrm{v}) \mathrm{DBM}$ and the water content significantly decreased with the addition of $2 \%$ (w/v) DBM (Figure 4b, c). Therefore, we selected two DBM concentration (1 and $2 \%$ ) to fabricate hydrogelDBM composite for further studies. Both ALP and mineral productions were enhanced with DBM incorporation as well as heparin functionalization (Figure 6a). In particular, expression of Runx2 was 
significantly enhanced in dual modification group (Hep-MeGC-DBM 2\%), indicating that DBM synergistically enhanced osteogenesis with heparin (Figure 6b). We also examined whether DBMhydrogel composite can sequester BMP-2 released from DBM. BMP-2 immunostaining results showed that heparinized chitosan was able to sequester BMP-2 not only secreted from the encapsulated cells, but also released from DBM (Figure S5).

In addition, DBM incorporation provided a cell-favorable environment in the hydrogels by increasing cell spreading and proliferation (Figure 5). The main component of DBM mass was a type I collagen which contributed to physical and biological properties to the matrix[41]. In our previous studies, the incorporation of type I collagen or its derivatives into MeGC could enhance the spreading, proliferation, and osteogenic differentiation of the encapsulated cells[23,42]. Herein, the observed increase in cell spreading and proliferation in the composites were possibly due to the incorporation of collagen matrix through DBM. Cell spreading become evident adjacent to DBM at 14 days of culture, while most cells remained round morphology in DBM-free hydrogels (MeGC-DBM 0\% and Hep-MeGC-DBM 0\%) over the culture period. Cell spreading in this study appeared to be slower and spatially non-uniform in comparison to our previous chitosan hydrogels modified with collagen or RGD peptides possibly due to the heterogeneous distribution of large DBM particles varied from $200-850 \mu \mathrm{m}$ throughout the hydrogel. The spreading and proliferation of the encapsulated cells were dominantly mediated by DBM incorporation rather than heparinization.

This study proposed a novel heparinized hydrogel carrier which stabilized BMP-2 bioactivity and improved DBM osteogenic efficacy. Bone healing capacity of DBM has not been successful in clinical situations where large quantity of bone regeneration is required. We will demonstrate the efficacy of DBM hydrogel composites for bone repair in more challenging healing environments such as in large segmental defects in comparison to currently available DBM products. Additionally, future study will employ additional approaches to abrogate BMP antagonism such as utilizing an RNAi strategy to downregulate noggin expression. These strategies could maximize activity of BMP pathway in DBMmediated osteogenesis and may increase the utility of a bone graft approach for improved bone repair. In addition, this heparinized platform could be utilized as functional polymeric carriers to deliver various proteins with heparin binding ability.

\section{Conclusions}

Heparinized chitosan was designed by simple conjugation and photopolymerization to provide a hydrogel surface that stabilized the bioactivity of BMP-2 and potentiated the osteogenic efficacy of DBM. Heparinization preserved BMP-2 bioactivity under stressors conditions mimicking a bone healing environment and protected BMP-2 from its antagonist, noggin. The heparinized hydrogel promoted endogenous BMP activity by sequestering the cell-produced BMPs. The heparinized system was effective to deliver DBM as composite hydrogels and further enhanced osteogenic differentiation of encapsulated cells induced by DBM. This study suggests a promising strategy to increase effectiveness of BMPs and 
utility of current bone graft approaches for improved bone regeneration in conjunction with polymeric carrier systems.

\section{Materials And Methods}

\section{Materials}

Glycol chitosan ( 100 kDa) was purchased from Wako Chemical USA, Inc. (Richmond, VA). Glycidyl methacrylate, heparin sodium salt from porcine intestinal mucosa (heparin, $18 \mathrm{kDa}$ ), and 1-ethyl-3-(3dimethyl- aminopropyl)-carbodiimide (EDC) were supplied from Sigma Aldrich (St. Louis, MO). Recombinant human bone morphogenetic protein-2 was supplied from GenScript (Piscataway, NJ). Recombinant human matrix metallopeptidase-9 (MMP-9) was purchased from abcam (Cambridge, MA) and recombinant mouse noggin/Fc chimera (Noggin) was purchased from R\&D Systems (Minneapolis, MN). Demineralized Bone Matrix (DBM; Demineralized Cortical Powder, 0.212 - $0.850 \mathrm{~mm}$ ) was provided from MTF Biologics (Edison, NJ). Mouse bone marrow stromal cells (BMSCs, D1 ORL UVA, CRL-12424) was obtained from American Type Culture Collection (ATCC, Manassas, VA). All reagents were used without further purification.

\section{Preparation of Heparinized Chitosan and Hydrogel-DBM composite}

Visible-light inducible methacrylated glycol chitosan (MeGC) was prepared by the previously published methods[26, 43]. Heparin conjugated glycidyl methacyrlated chitosan (Hep-MeGC) was prepared by EDC activated reaction of heparin and MeGC. EDC solution was prepared as $23 \mathrm{mg}$ in $1 \mathrm{~mL}$ distilled water and reacted with $8 \mathrm{mg}$ of heparin for $30 \mathrm{~min}$. Then, the reacted solution was mixed with $5 \mathrm{~mL}$ of $1 \%(\mathrm{w} / \mathrm{v})$ MeGC in PBS for $16 \mathrm{~h}$, dialyzed with $50 \mathrm{kDa}$ tubes for $16 \mathrm{~h}$ and lyophilized. Hydrogel-DBM composites incorporated hydrogel and DBM in various weight ratio, $0,0.5,1,2$, and $4 \%(w / v)$, based on $2 \%(w / v)$ hydrogel concentration. All hydrogels were fabricated by $40 \mathrm{~s}$ irradiation of hydrogel prepolymer and 6 $\mu \mathrm{M}$ riboflavin initiator (100:0.5 volume ratio) under visible blue light (400 - $500 \mathrm{~nm}, 300 \mathrm{~mW} \mathrm{~cm}{ }^{-2}$ ) irradiation.

\section{Characterization of Heparinized Chitosan and Hydrogel-DBM composite}

Heparin conjugation was analyzed by ${ }^{1} \mathrm{H}$ nuclear magnetic resonance spectroscopy (NMR) in $\mathrm{D}_{2} \mathrm{O}$ (Bruker ARX400 spectrometer). It was quantified by the integration of the peaks at $2.7-3.2 \mathrm{ppm}\left(\mathrm{CHNHSO}^{3-}\right.$, $\mathrm{CHOSO}^{3-}, \mathrm{CH}_{2} \mathrm{OSO}^{3-}$ ) and compared with methacrylate peak at $5.6-6.1 \mathrm{ppm}$. The degree of heparin substitution was reported as $6.76 \%$. Heparinized chitosan was also characterized by fourier transform infrared spectrophotometer (FTIR, Jasco 420) to verify the heparin conjugation. The incorporation of 
heparin over time was examined by toluidine blue (Sigma-Aldrich, MO) staining that the hydrogels were stained with $1 \%(\mathrm{w} / \mathrm{v})$ toluidine blue in PBS and washed with PBS for $1 \mathrm{~h}$.

Mechanical properties of composites were measured by compressive modulus and water content. The compressive modulus was evaluated by $1.6 \mathrm{~mm}$ diameter flat-ended indentation test via Instron Electro- Mechanical Testing Machines (Instron, Model 5564, Norwood, MA) using a Poisson's ratio of $0.25[26,43]$. Water content was calculated by the following equation where and referred wet and dry weight of hydrogels respectively.

[Please see supplementary files to access the equation.]

\section{Alkaline Phosphatase Staining and Activity}

Bioactivity of BMP-2 and osteogenic efficacy of MeGC, Hep-MeGC, and composites were evaluated by alkaline phosphatase (ALP) staining and activity. First of all, $100 \mathrm{ng} \mathrm{mL}^{-1}$ of rhBMP-2 was incubated in the presence of $10 \mu \mathrm{L}$ of MeGC or Hep-MeGC under different stressed conditions of $37^{\circ} \mathrm{C}$ for 7 days or $200 \mathrm{ng} \mathrm{mL}^{-1}$ of MMP-9 for $16 \mathrm{~h}$. Then, $100 \mathrm{ng} \mathrm{mL}^{-1}$ of incubated rhBMP-2 was treated to BMSCs in osteogenic media (OM) including high glucose Dulbecco's Modified Eagle's Medium, 10\% fetal bovine serum, $1 \%$ antibiotic-antimycotic, $10 \mathrm{mM}$ ß-glycerophosphate, $50 \mathrm{mg} \mathrm{mL}^{-1} \mathrm{~L}$-ascorbic acid, and $100 \mathrm{nM}$ dexamethasone for 4 days. Second, $100 \mathrm{ng} \mathrm{mL}^{-1}$ of rhBMP-2 was incubated in the presence of $10 \mu \mathrm{L}$ of MeGC or Hep-MeGC with noggin $\left(0,30,100\right.$, and $\left.300 \mathrm{ng} \mathrm{mL}^{-1}\right)$ for 4 days. After all the culture, BMSCs were fixed with $10 \%$ formalin and incubated in solution containing nitro blue tetrazolium, 5-bromo-4chloro-3-in doxylphosphate, $100 \mathrm{mM}$ Tris (pH 8.5), $50 \mathrm{mM} \mathrm{MgCl}_{2}$, and $100 \mathrm{mM} \mathrm{NaCl}$ for $3 \mathrm{~h}$. ALP activity was evaluated by colorimetric analysis using $p$-nitrophenol phosphate as a substrate. The value was read at $405 \mathrm{~nm}$ and normalized by total protein expression from BCA assay[23, 44].

\section{Real-time Reverse Transcription Polymerase Chain Reaction (qRT-PCR)}

The induced noggin expression by MeGC or Hep-MeGC and osteogenic efficacy of composites were examined by qRT-PCR. The RNAs were extracted from BMSCs by TRIzol (Invitrogen, CA) and RNeasy mini kit (Qiagen, CA), and then reverse-transcribed by SuperScript III kit (Invitrogen, CA). The cDNA products were amplified for 45 cycles with SYBR green in LightCycler 480 PCR system (Indianapolis, IN). The value was normalized with GAPDH expression and the primer sequences are: GAPDH (AGgTCGgTGTGAACGgATTTG and TGTAGACCATGTAGTTGAGGTCA), Noggin (GCCAGCACTATCTACACATCC and GCGTCTCGTCAGATCCTTCT), Runx2 (CGGTCTCCTTCCAGGATGGT and GCTTCCGTCAGCGTCAACA), ALP(GTTGCCAAGCTGGGAAGAACAC and CCCACCCCGCTATTCCAAAC), and OCN (GGGAGACAACAGGGAGGAAAC and CAGGCTTCCTGCCAGTACCT). All experiments were triplicated. 


\section{Proliferation of Cells in Hydrogel-DBM composite}

The BMSCs were encapsulated in composites with concentration of $210^{6}$ cells mL $\mathrm{mL}^{-1}$. The base hydrogels, MeGC and Hep-MeGC, were mixed with various DBM ratio, 0,1 , and $2 \%(w / v)$ in $2 \%(w / v)$ hydrogel. The BMSCs encapsulated in hydrogels were cultured in culture media for two weeks at $37^{\circ} \mathrm{C}$. The morphology of BMSCs were monitored by Live/Dead staining kit (Invitrogen, CA) at day 0, 7, and 14 and proliferative potential was measured by alamarBlue (Thermo Fisher Scientific, CA) assay at day 0, 1, 7 , and 14. To investigate the further morphology change of cells near DBM, hydrogels at day 14 were fixed with $10 \%$ formalin for overnight, embedded in paraffin, and cut into $5 \mu \mathrm{m}$ section. The sections were stained with hematoxylin and eosin (H\&E) after deparaffinizing.

\section{Osteogenic Differentiation of Cells in Hydrogel-DBM composite}

The BMSCs encapsulated in composites were incubated in $\mathrm{OM}$ for 21 days to induce osteogenesis. The samples were collected at day 7 for ALP staining and activity test. At day 21, the mineral deposition in the samples were measured by alizarin red S staining after fixation. The hydrogels were incubated in $2 \%$ alizarin red S solution for 5 min and washed with PBS for overnight. All stained hydrogels were visualized by Olympus SZX16 stereo microscope. Calcium quantification was carried out by acetic acid extraction of alizarin red $S$ stained hydrogels[45].

\section{Statistical Analysis}

All experiments were executed three times and represented as values with error bars which were the average and the standard deviation. One- or two-way analysis of variance with Tukey's post hoc test was used for statistical analysis. A value of $p<0.05$ was considered as significant.

\section{Additional File Information}

Additional File 1: Figure S1. Relative ALP expression of BMSCs cultured with graded dosages of noggin, BMP-2, and either MeGC or Hep-MeGC (corresponding to Figure 3a). ${ }^{\star} p<0.05$, ${ }^{\star \star} p<0.01$, and ${ }^{* \star \star} p<$ 0.001 .

Additional File 2: Figure S2. The dead staining images of hydrogel-DBM composites (corresponding to Figure $5 \mathrm{a}$ ). Scale bar is $200 \mu \mathrm{m}$. The cell viability for day 14 was quantified based on live and dead cells number using ImageJ. N.S., Not significant. ${ }^{\star} p<0.05$. 
Additional File 3: Figure S3. H\&E staining images of hydrogel-DBM composites. The " $\mathrm{H}$ " indicates the location of hydrogel and "D" indicates the location of DBM with the proliferated cells. Scale bar is $50 \mu \mathrm{m}$.

Additional File 4: Figure S4. Half-life extension of BMP-2 induced by Hep-MeGC. BMSCs were cultured with $100 \mathrm{ng} \mathrm{mL}^{-1}$ of BMP-2 with MeGC (blue) and Hep-MeGC (orange) for prolonged condition and with $200 \mathrm{ng} \mathrm{mL}^{-1}$ MMP-9 for proteolysis condition. The concentration of BMP-2 near cell layer were quantified by BMP-2 enzyme-linked immunosorbent assay.

Additional File 5: Figure S5. BMP-2 immunostaining of hydrogel-DBM composites without or with the encapsulated cells after one-week incubation. Scale bar is $200 \mu \mathrm{m}$.

\section{List Of Abbreviations}

DBM: Demineralized bone batrix, BMP: Bone morphogenetic proteins, MeGC: Methacrylated glycol chitosan, Hep-MeGC: Heparin conjugated glycidyl methacyrlated chitosan, EDC: 1-Ethyl-3-(3-dimethylaminopropyl)-carbodiimide, MMP-9: Matrix metallopeptidase-9, BMSCs: Bone marrow stromal cells, FTIR: Fourier transform infrared spectrophotometer, NMR: Nuclear magnetic resonance spectroscopy, ALP: Alkaline phosphatase, OM: Osteogenic media, qRT-PCR: Real-time reverse transcription polymerase chain reaction

\section{Declarations}

\section{Ethics approval and consent to participate}

Not applicable.

\section{Consent for publication}

Not applicable.

\section{Availability of data and material}

The datasets used and/or analyzed during the current study are available from the corresponding author on reasonable request.

\section{Competing interests}

The authors declare that they have no competing interests. 


\section{Funding}

This work was supported by grants from the National Institutes of Health (R01 DE027332), the Department of Defense (W81XWH-18-1-0337), and the MTF Biologics.

\section{Authors' contributions}

SK conducted the experiments, participated in data analysis and discussion, and drafted the manuscript. JF and CL participated in discussion and revised the manuscript. CC and KB carried out DBM experiments. ML designed the experiments and drafted the manuscript. All authors read and approved the final manuscript.

\section{Acknowledgements}

Not applicable.

\section{Authors' information}

${ }^{1}$ Division of Advanced Prosthodontics, University of California, Los Angeles, USA

${ }^{2}$ Department of Bioengineering, University of California, Los Angeles, USA

\section{References}

1. Pape HC, Evans A, Kobbe P: Autologous bone graft: properties and techniques. J Orthop Trauma 2010, 24 Suppl 1:S36-40.

2. Ladd AL, Pliam NB: Use of bone-graft substitutes in distal radius fractures. J Am Acad Orthop Surg 1999, 7:279-290.

3. Kuhls R, Werner-Rustner M, Küchler I, Soost F: Human demineralised bone matrix as a bone substitute for reconstruction of cystic defects of the lower jaw. Cell Tissue Bank 2001, 2:143-153.

4. Wildemann B, Kadow-Romacker A, Haas NP, Schmidmaier G: Quantification of various growth factors in different demineralized bone matrix preparations. J Biomed Mater Res A 2007, 81:437-442.

5. Pieske O, Wittmann A, Zaspel J, Löffler T, Rubenbauer B, Trentzsch H, Piltz S: Autologous bone graft versus demineralized bone matrix in internal fixation of ununited long bones. $J$ Trauma Manag Outcomes 2009, 3:11. 
6. Chesmel KD, Branger J, Wertheim H, Scarborough $\mathrm{N}$ : Healing response to various forms of human demineralized bone matrix in athymic rat cranial defects. J Oral Maxillofac Surg 1998, 56:857-863; discussion 864-855.

7. Shehadi JA, Elzein SM: Review of commercially available demineralized bone matrix products for spinal fusions: A selection paradigm. Surg Neurol Int 2017, 8:203.

8. Francis CS, Mobin SS, Lypka MA, Rommer E, Yen S, Urata MM, Hammoudeh JA: rhBMP-2 with a demineralized bone matrix scaffold versus autologous iliac crest bone graft for alveolar cleft reconstruction. Plast Reconstr Surg 2013, 131:1107-1115.

9. James AW, LaChaud G, Shen J, Asatrian G, Nguyen V, Zhang XL, Ting K, Soo C: A Review of the Clinical Side Effects of Bone Morphogenetic Protein-2. Tissue Engineering Part B-Reviews 2016, 22:284-297.

10. Tang TT, Xu XL, Dai KR, Yu CF, Yue B, Lou JR: Ectopic bone formation of human bone morphogenetic protein-2 gene transfected goat bone marrow-derived mesenchymal stem cells in nude mice. Chin $J$ Traumatol 2005, 8:3-7.

11. Choudhry OJ, Christiano LD, Singh R, Golden BM, Liu JK: Bone morphogenetic protein-induced inflammatory cyst formation after lumbar fusion causing nerve root compression Case report. Journal of Neurosurgery-Spine 2012, 16:296-301.

12. Tachi K, Takami M, Zhao B, Mochizuki A, Yamada A, Miyamoto Y, Inoue T, Baba K, Kamijo R: Bone morphogenetic protein 2 enhances mouse osteoclast differentiation via increased levels of receptor activator of NF-kappa B ligand expression in osteoblasts. Cell and Tissue Research 2010, 342:213220.

13. Sottile V, Seuwen K: Bone morphogenetic protein-2 stimulates adipogenic differentiation of mesenchymal precursor cells in synergy with BRL 49653 (rosiglitazone). Febs Letters 2000, 475:201204.

14. Jeon O, Song SJ, Yang HS, Bhang S-H, Kang S-W, Sung MA, Lee JH, Kim B-S: Long-term delivery enhances in vivo osteogenic efficacy of bone morphogenetic protein-2 compared to short-term delivery. Biochemical and Biophysical Research Communications 2008, 369:774-780.

15. Rider CC: Heparin/heparan sulphate binding in the TGF-beta cytokine superfamily. Biochemical Society Transactions 2006, 34:458-460.

16. Ruppert R, Hoffmann E, Sebald W: Human bone morphogenetic protein 2 contains a heparin-binding site which modifies its biological activity. European Journal of Biochemistry 1996, 237:295-302.

17. Takada T, Katagiri T, Ifuku M, Morimura N, Kobayashi M, Hasegawa K, Ogamo A, Kamijo R: Sulfated polysaccharides enhance the biological activities of bone morphogenetic proteins. J Biol Chem 2003, 278:43229-43235.

18. Kuo WJ, Digman MA, Lander AD: Heparan sulfate acts as a bone morphogenetic protein coreceptor by facilitating ligand-induced receptor hetero-oligomerization. Mol Biol Cel/ 2010, 21:4028-4041.

19. Groppe J, Greenwald J, Wiater E, Rodriguez-Leon J, Economides AN, Kwiatkowski W, Affolter M, Vale WW, Izpisua Belmonte JC, Choe S: Structural basis of BMP signalling inhibition by the cystine knot 
protein Noggin. Nature 2002, 420:636-642.

20. Paine-Saunders S, Viviano BL, Economides AN, Saunders S: Heparan sulfate proteoglycans retain Noggin at the cell surface: a potential mechanism for shaping bone morphogenetic protein gradients. J Biol Chem 2002, 277:2089-2096.

21. Zhao BH, Katagiri T, Toyoda H, Takada T, Yanai T, Fukuda T, Chung Ul, Koike T, Takaoka K, Kamijo R: Heparin potentiates the in vivo ectopic bone formation induced by bone morphogenetic protein-2. Journal of Biological Chemistry 2006, 281:23246-23253.

22. Kumar M, Muzzarelli RAA, Muzzarelli C, Sashiwa H, Domb AJ: Chitosan Chemistry and Pharmaceutical Perspectives. Chemical Reviews 2004, 104:6017-6084.

23. Kim S, Cui ZK, Fan JB, Fartash A, Aghaloo TL, Lee M: Photocrosslinkable Chitosan Hydrogels Functionalized with the RGD Peptide and Phosphoserine to Enhance Osteogenesis. Journal of Materials Chemistry B 2016, 4:5289-5298.

24. Cao LY, Werkmeister JA, Wang J, Glattauer V, McLean KM, Liu CS: Bone regeneration using photocrosslinked hydrogel incorporating rhBMP-2 loaded 2-N, 6-0-sulfated chitosan nanoparticles. Biomaterials 2014, 35:2730-2742.

25. Tian M, Yang Z, Kuwahara K, Nimni ME, Wan C, Han B: Delivery of demineralized bone matrix powder using a thermogelling chitosan carrier. Acta Biomater 2012, 8:753-762.

26. Hu J, Hou Y, Park H, Choi B, Hou S, Chung A, Lee M: Visible Light Crosslinkable Chitosan Hydrogels for Tissue Engineering. Acta Biomater 2012, 8:1730-1738.

27. LogithKumar R, KeshavNarayan A, Dhivya S, Chawla A, Saravanan S, Selvamurugan N: A review of chitosan and its derivatives in bone tissue engineering. Carbohydr Polym 2016, 151:172-188.

28. Kim S, Cui ZK, Koo B, Zheng J, Aghaloo T, Lee M: Chitosan-Lysozyme Conjugates for EnzymeTriggered Hydrogel Degradation in Tissue Engineering Applications. ACS App/ Mater Interfaces 2018.

29. Gazzerro E, Gangji V, Canalis E: Bone morphogenetic proteins induce the expression of noggin, which limits their activity in cultured rat osteoblasts. J Clin Invest 1998, 102:2106-2114.

30. Kenley R, Marden L, Turek T, Jin L, Ron E, Hollinger JO: OSSEOUS REGENERATION IN THE RAT CALVARIUM USING NOVEL DELIVERY SYSTEMS FOR RECOMBINANT HUMAN BONE MORPHOGENETIC PROTEIN-2 (RHBMP-2). Journal of Biomedical Materials Research 1994, 28:11391147.

31. Marden LJ, Hollinger JO, Chaudhari A, Turek T, Schaub RG, Ron E: Recombinant human bone morphogenetic protein-2 is superior to demineralized bone matrix in repairing craniotomy defects in rats. J Biomed Mater Res 1994, 28:1127-1138.

32. Ortega N, Behonick D, Stickens D, Werb Z: How proteases regulate bone morphogenesis. Ann N Y Acad Sci 2003, 995:109-116.

33. Vu TH, Werb Z: Matrix metalloproteinases: effectors of development and normal physiology. Genes Dev 2000, 14:2123-2133. 
34. Tchetverikov I, Lohmander LS, Verzijl N, Huizinga TW, TeKoppele JM, Hanemaaijer R, DeGroot J: MMP protein and activity levels in synovial fluid from patients with joint injury, inflammatory arthritis, and osteoarthritis. Ann Rheum Dis 2005, 64:694-698.

35. Kochetkova EA, Ugaĭ LG, Maĭstrovskaia IV, Buria KA, Nevzorova VA: Role of matrix metalloproteinase9 in the pathogenesis of osteoporosis in patients with chronic obstructive pulmonary disease. Ter Arkh 2012, 84:37-40.

36. Thrailkill K, Cockrell G, Simpson P, Moreau C, Fowlkes J, Bunn RC: Physiological matrix metalloproteinase (MMP) concentrations: comparison of serum and plasma specimens. Clin Chem Lab Med 2006, 44:503-504.

37. Masuhara K, Nakai T, Yamaguchi K, Yamasaki S, Sasaguri Y: Significant increases in serum and plasma concentrations of matrix metalloproteinases 3 and 9 in patients with rapidly destructive osteoarthritis of the hip. Arthritis Rheum 2002, 46:2625-2631.

38. Hu Z, Ma C, Liang Y, Zou S, Liu X: Osteoclasts in bone regeneration under type 2 diabetes mellitus. Acta Biomater 2019, 84:402-413.

39. Abe E, Yamamoto M, Taguchi Y, Lecka-Czernik B, O'Brien CA, Economides AN, Stahl N, Jilka RL, Manolagas SC: Essential requirement of BMPs-2/4 for both osteoblast and osteoclast formation in murine bone marrow cultures from adult mice: antagonism by noggin. $J$ Bone Miner Res 2000 , 15:663-673.

40. Viviano BL, Paine-Saunders S, Gasiunas N, Gallagher J, Saunders S: Domain-specific modification of heparan sulfate by Qsulf1 modulates the binding of the bone morphogenetic protein antagonist Noggin. J Biol Chem 2004, 279:5604-5611.

41. Holt DJ, Grainger DW: Demineralized bone matrix as a vehicle for delivering endogenous and exogenous therapeutics in bone repair. Adv Drug Deliv Rev 2012, 64:1123-1128.

42. Arakawa C, Ng R, Tan S, Kim S, Wu B, Lee M: Photopolymerizable Chitosan-Collagen Hydrogels for Bone Tissue Engineering. J Tissue Eng Regen Med 2017, 11:164-174.

43. Amsden BG, Sukarto A, Knight DK, Shapka SN: Methacrylated Glycol Chitosan as a Photopolymerizable Biomaterial. Biomacromolecules 2007, 8:3758-3766.

44. Sabokbar A, Millett PJ, Myer B, Rushton N: A rapid, quantitative assay for measuring alkaline phosphatase activity in osteoblastic cells in vitro. Bone Miner 1994, 27:57-67.

45. Cui Z-K, Kim S, Baljon JJ, Wu BM, Aghaloo T, Lee M: Microporous methacrylated glycol chitosanmontmorillonite nanocomposite hydrogel for bone tissue engineering. Nature Communications 2019, 10:3523.

\section{Figures}


a
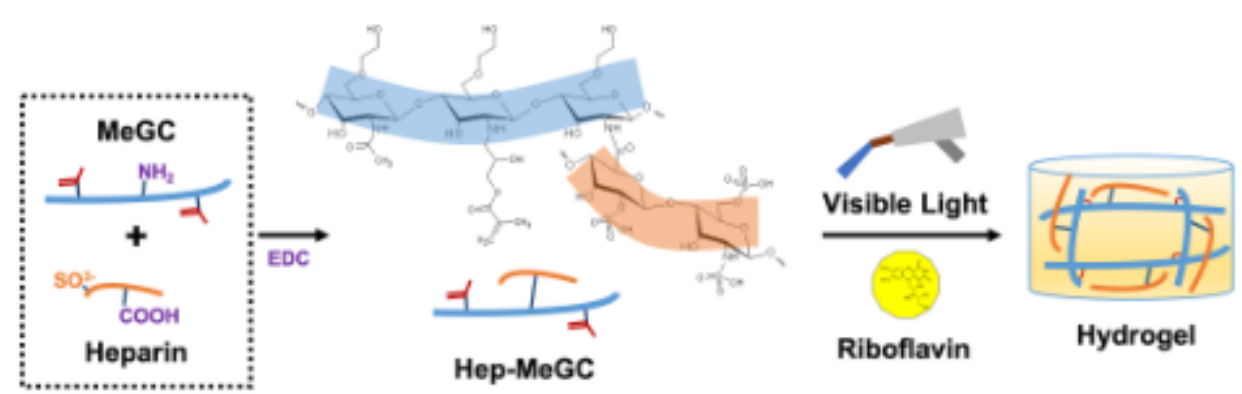

b
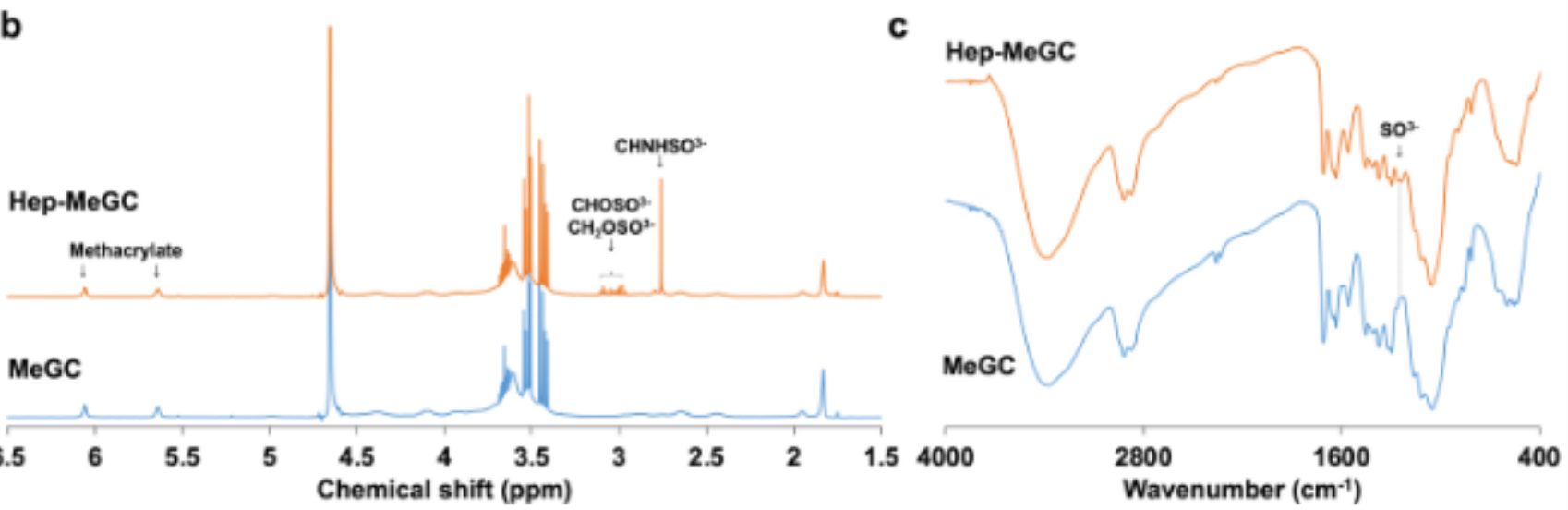

d
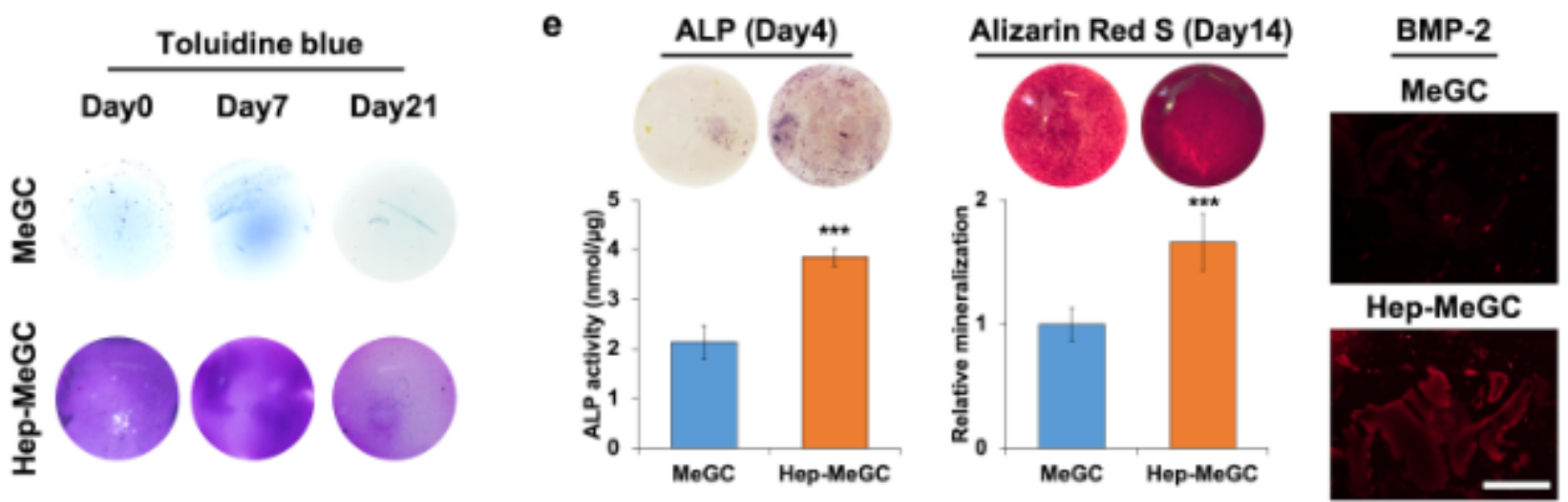

Figure 1

Characterization of heparinized chitosan (Hep-MeGC). (a) Chemical reaction to prepare Hep-MeGC from MeGC and heparin via EDC reaction, and visible-light induced hydrogel fabrication with riboflavin as a photoiniator. (b) 1H NMR spectra of MeGC and Hep-MeGC (400 MHz, D20) to verify heparin conjugation. (c) FTIR spectra of MeGC and Hep-MeGC to confirm heparin conjugation. (d) Toluidine blue staining images for three weeks to confirm stable incorporation and homogenous distribution of conjugated heparin in hydrogels. (e) Osteogenic efficacy of Hep-MeGC with encapsulated BMSCs. ALP staining and activity at day 4 . Alizarin red S staining and relative mineralization at day 14 . Immunostaining of BMP-2 in hydrogels encapsulated with BMSCs to demonstrate the sequestering ability of hydrogel. Scale bar is $200 \mu \mathrm{m} .{ }^{* \star *} \mathrm{p}<0.001$. 

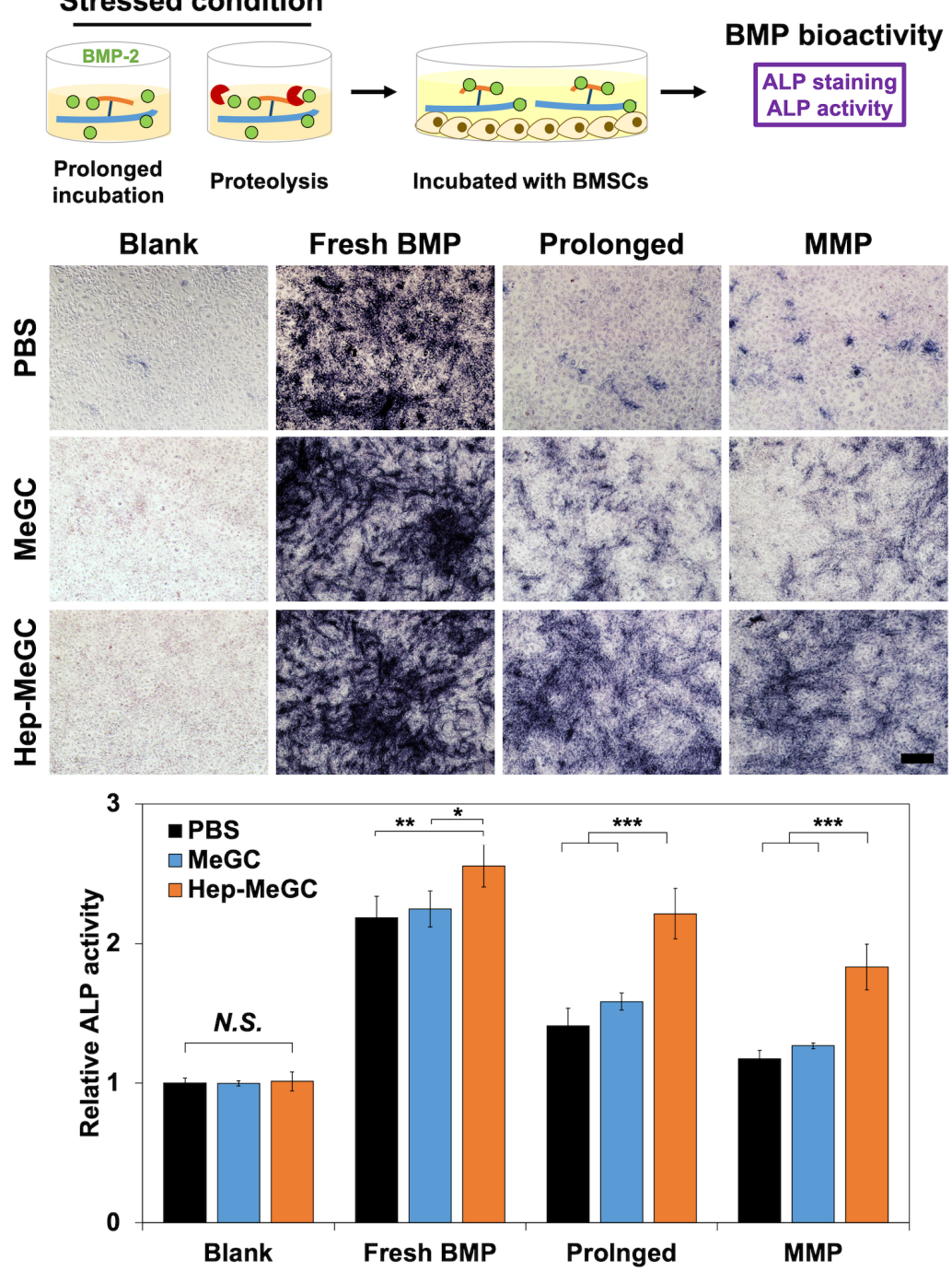

b
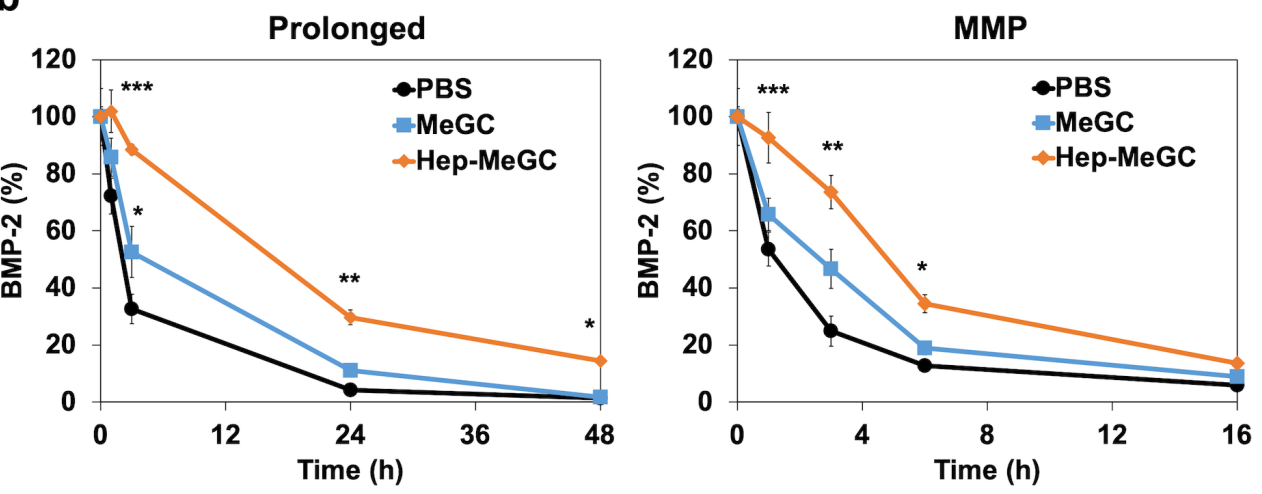

Figure 2

BMP-2 bioactivity test under stressed conditions. (a) The BMP-2 was incubated in prolonged condition, $37 \mathrm{oC}$ for a week, and proteolysis environment, $200 \mathrm{ng} \mathrm{mL}-1$ of MMP-9 for $16 \mathrm{~h}$, in the presence of HepMeGC. Then, it was treated with BMSCs for 4 days, and ALP staining and activity test were performed respectively to verify the bioactivity of BMP-2. N.S., Not significant. ${ }^{\star} p<0.05,{ }^{\star \star} p<0.01$, and ${ }^{\star \star \star} p<0.001$. Scale bar is $100 \mu \mathrm{m}$. (b) Half-life extension of BMP-2 induced by Hep-MeGC. BMSCs were cultured with 
100 ng mL-1 of BMP-2 with MeGC (blue) and Hep-MeGC (orange) for prolonged condition and with 200 ng mL-1 MMP-9 for proteolysis condition. The concentration of BMP-2 in culture medium were quantified by BMP-2 enzyme-linked immunosorbent assay. ${ }^{*} p<0.05$, ${ }^{*} p<<0.01$, and ${ }^{* *} p<0.001$ compared to PBS group.

a

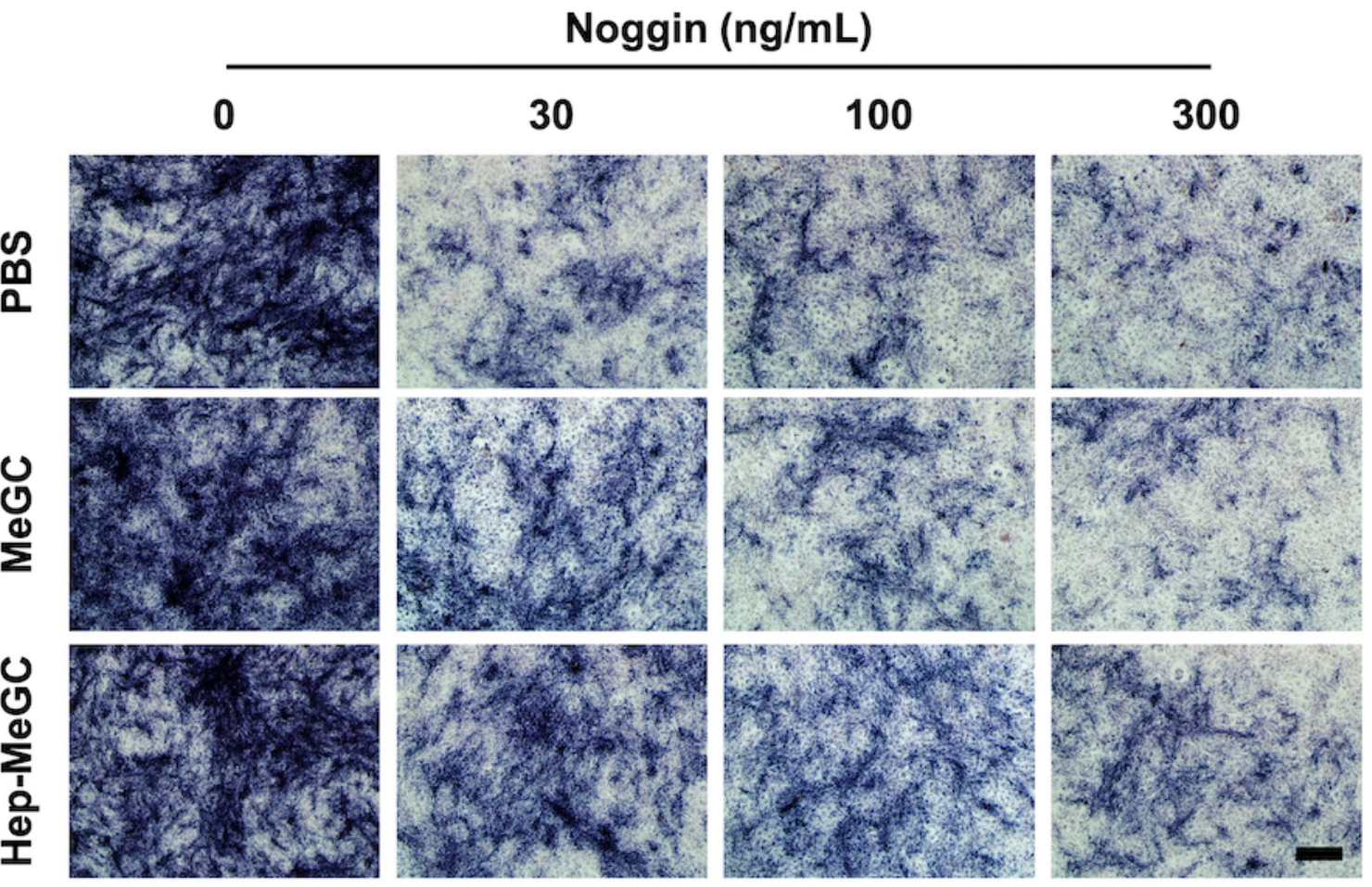

b

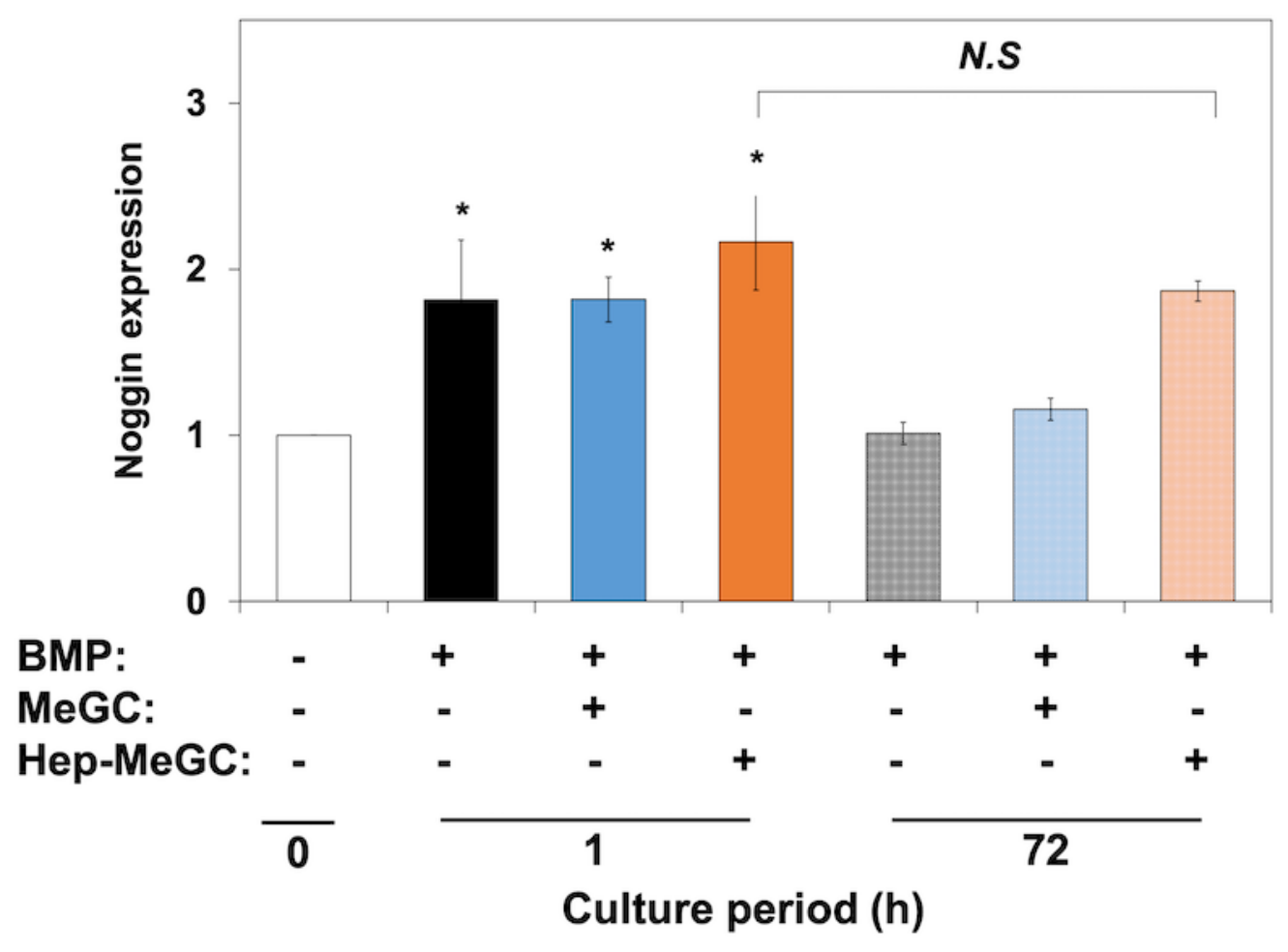

Figure 3 
Protection effect of BMP-2 from noggin. (a) ALP staining of BMSCs cultured with graded dosages of noggin, BMP-2, and either MeGC or Hep-MeGC. Scale bar is $100 \mu \mathrm{m}$. (b) Noggin gene expression induced by BMP-2 in BMSCs. BMSCs were treated with BMP-2 up to 72 h. N.S., Not significant. ${ }^{*} \mathrm{p}<0.05$ compared to the negative control (white bar).

a

DBM (\%)

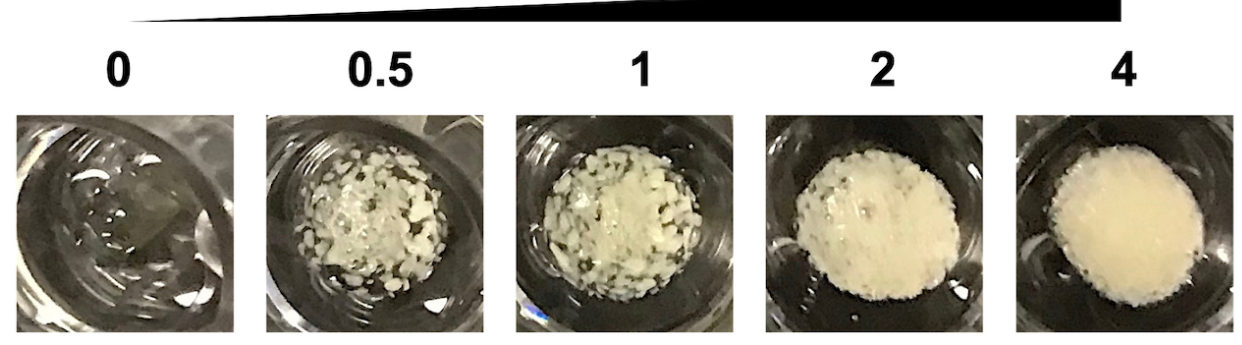

b

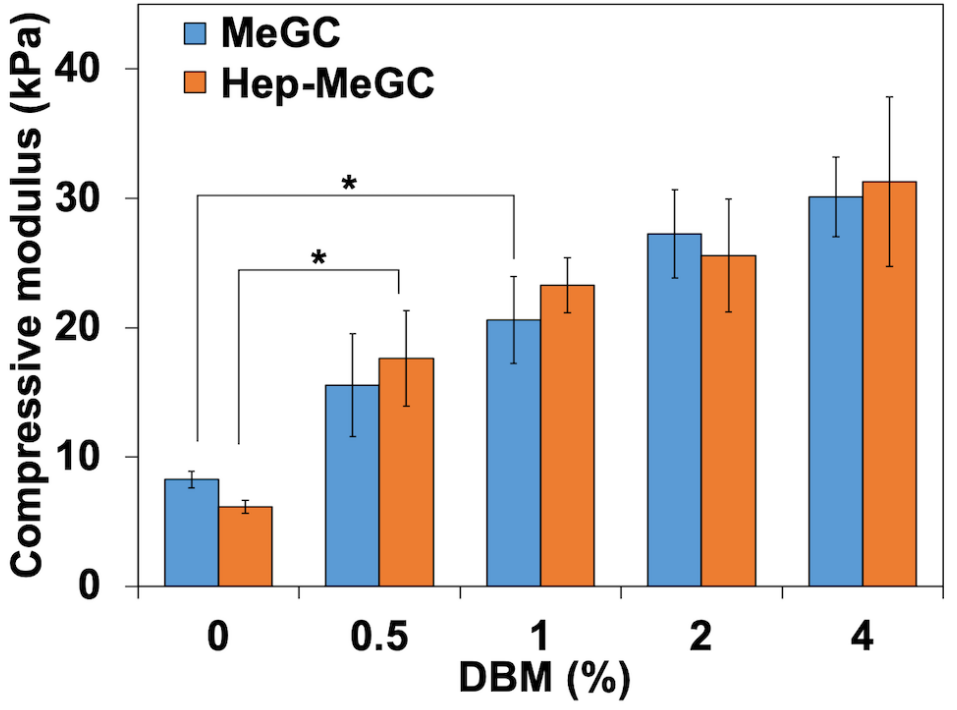

C

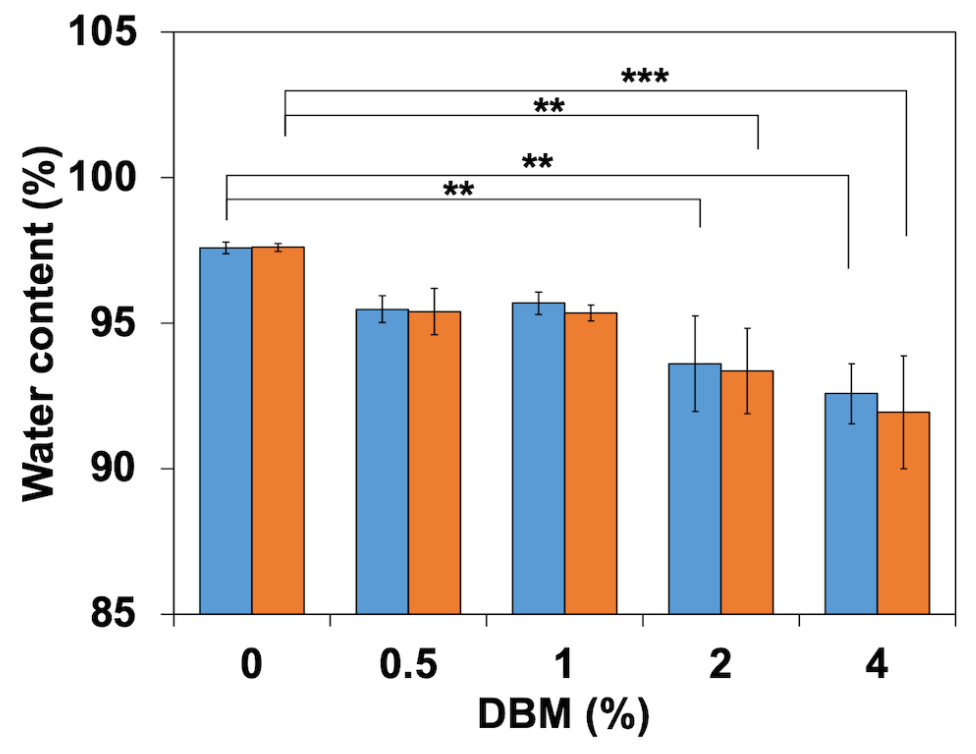

Figure 4 
Characterization of hydrogel-DBM composites. (a) The images of composites with various concentration of DBM weight ratio, $0,0.5,1,2$, and $4 \%(\mathrm{w} / \mathrm{v})$ in $2 \%$ hydrogel. (b) Compressive modulus of MeGC-DBM and Hep-MeGC-DBM composites. (c) Water content of composites. ${ }^{*} p<0.05$, ${ }^{* *} p<0.01$, and ${ }^{* * *} p<0.001$.

a

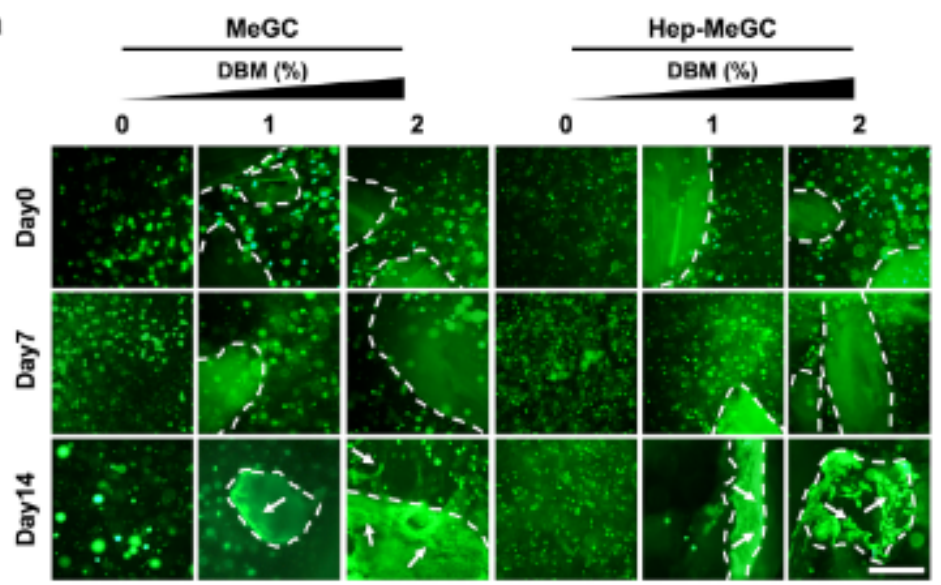

b

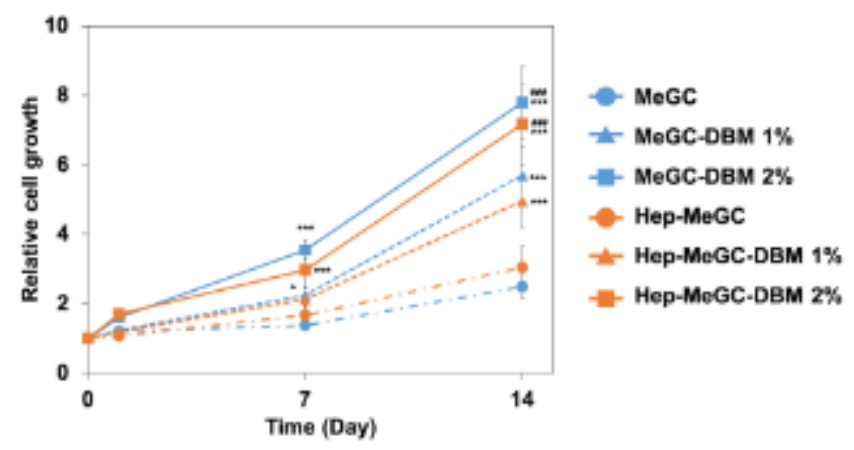

c

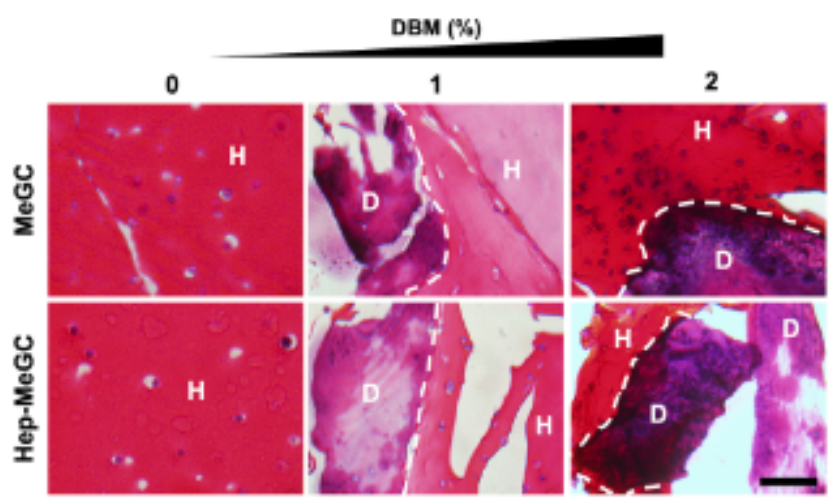

\section{Figure 5}

Proliferative potential of BMSCs in hydrogel-DBM composites. (a) Morphological observation of BMSCs in composites. Dotted lines demarcate the DBM/hydrogel interface and arrows point to spreading cells. Scale bar is $200 \mu \mathrm{m}$. (b) The proliferative potential of BMSCs measured by alamarBlue. (*) compared to MeGC or Hep-MeGC and (\#) compared to MeGC-DBM 1\% or Hep-MeGC-DBM 1\%. ${ }^{\star} p<0.05,{ }^{* \star} p<0.001$, and \#\#\#p < 0.001. (c) H\&E staining images of BMSCs cultured in composites for two weeks to observe the internal structure of cells and composites. Dotted lines demarcate the DBM/hydrogel interface $(\mathrm{H}$ : Hydrogel, D: DBM). Scale bar is $50 \mu \mathrm{m}$. 
a
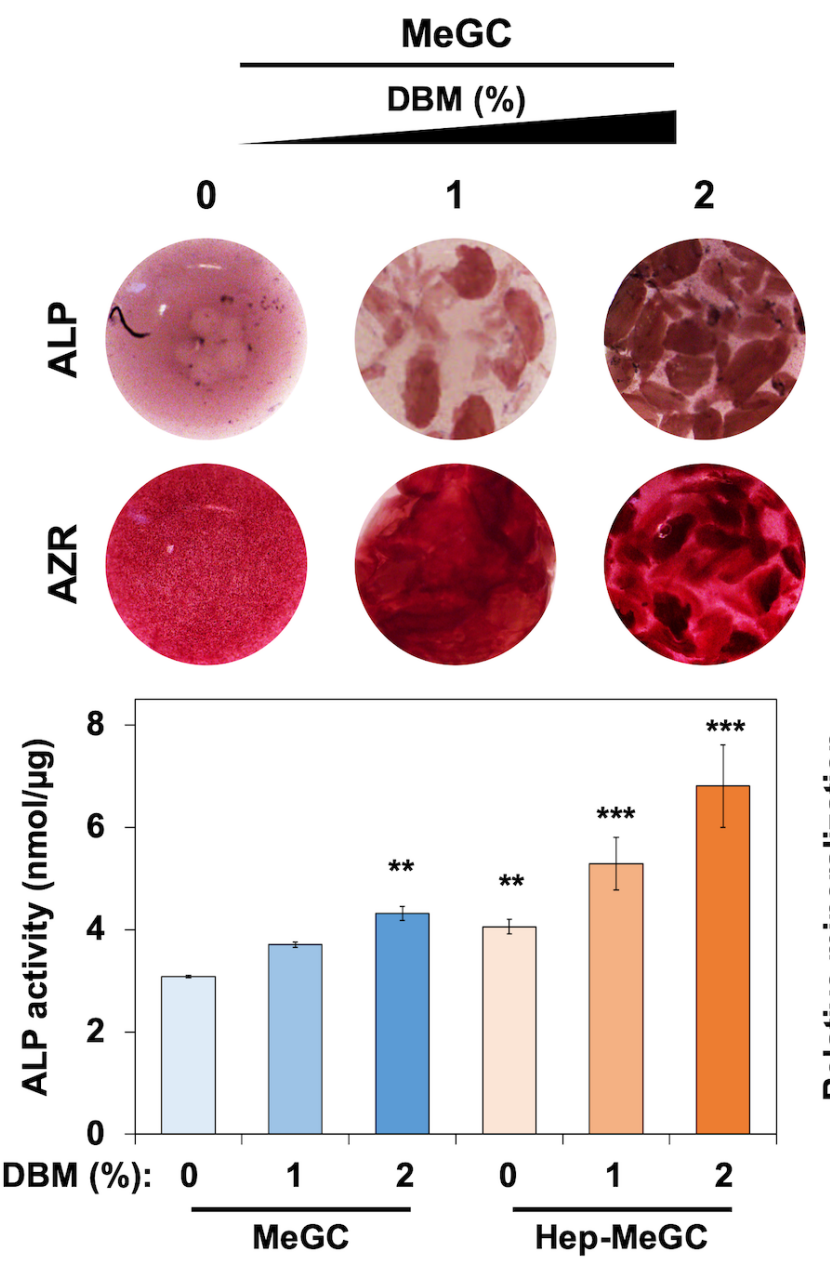
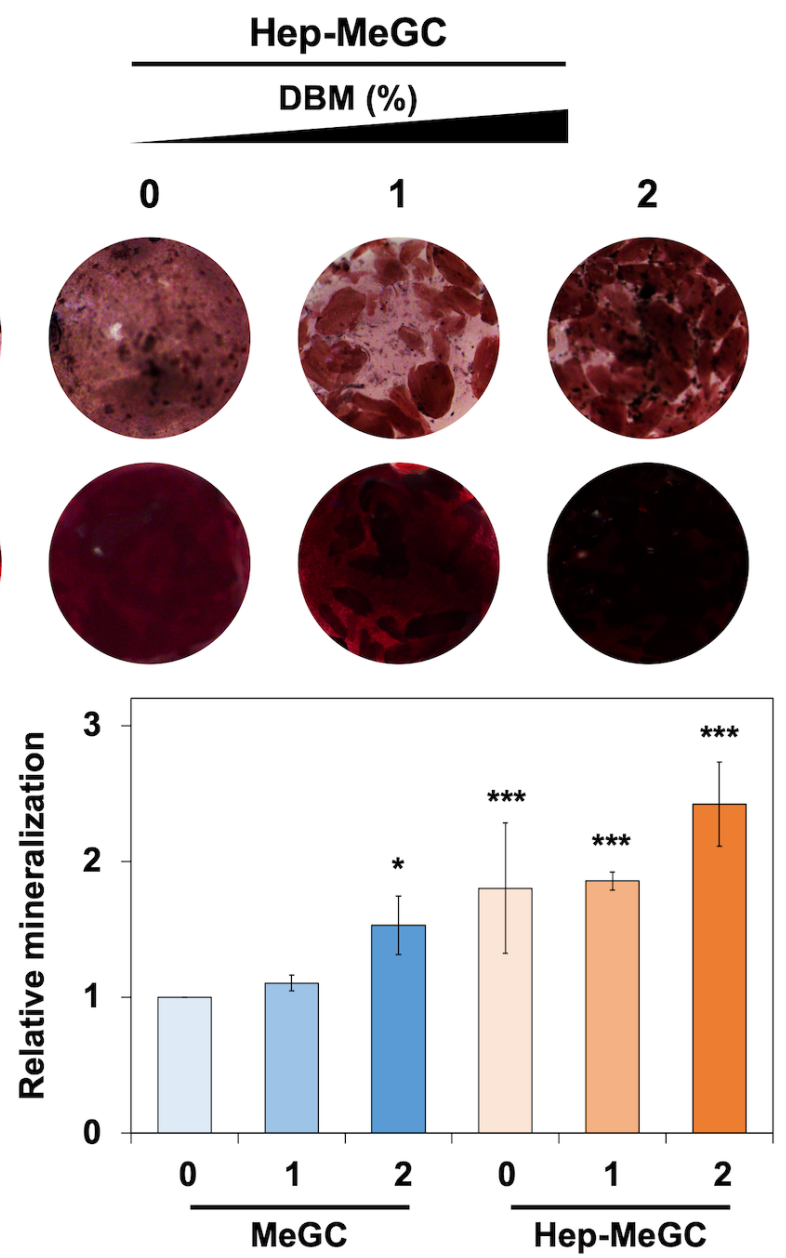

b

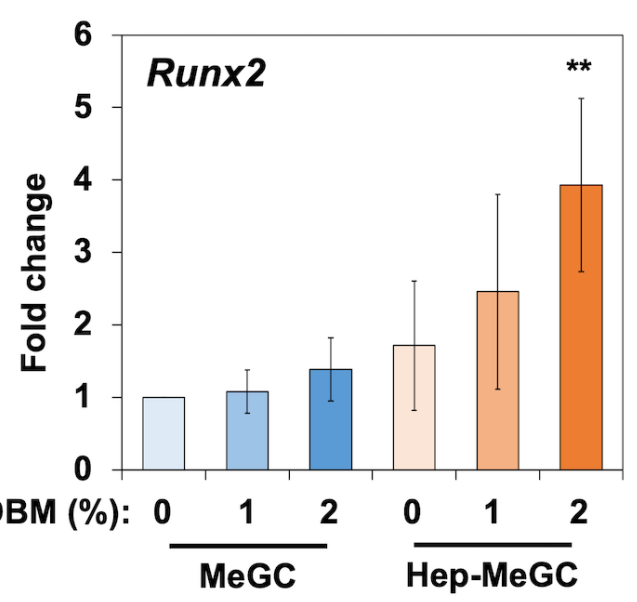

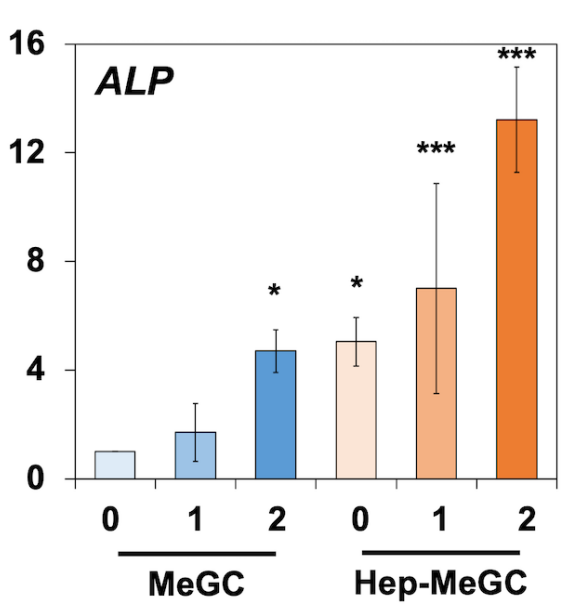

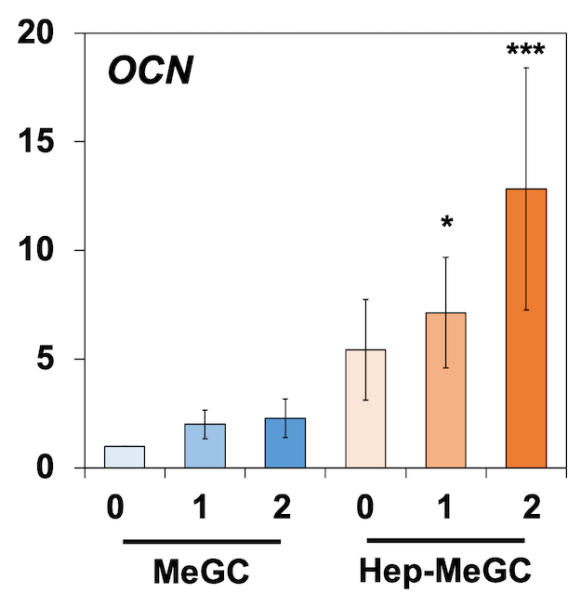

\section{Figure 6}

Osteogenic efficacy of hydrogel-DBM composites. (a) ALP (top) at one week and alizarin red S (bottom) at three weeks staining images of composites. ALP activity and relative mineralization were evaluated at the same day of staining. ${ }^{*} p<0.05,{ }^{*} p<0.01$, and ${ }^{* \star *} p<0.001$ compared to DBM-free group (MeGCDBM 0\%). (b) Osteogenic gene expression measured by qRT-PCR at day 4 (Runx2 and ALP), day 21 
(OCN), compared to MeGC. ${ }^{\star} \mathrm{p}<0.05,{ }^{\star \star} \mathrm{p}<0.01$, and ${ }^{* \star *} \mathrm{p}<0.001$ compared to DBM-free group (MeGCDBM 0\%).

\section{Supplementary Files}

This is a list of supplementary files associated with this preprint. Click to download.

- Equation.docx

- AdditionalFile.docx 